\title{
In This Issue: Research Briefs and New Clinical and Policy Insights
}

\author{
Kurt C. Stange, $M D, P b D$, Editor \\ Ann Fam Med 2014;12:498-499. doi: 10.1370/afm.1718.
}

\section{RESEARCH BRIEFS-A NEW FEATURE IN ANNALS}

I $\mathrm{n}$ this issue, we launch a new Annals featureResearch Briefs. Research Briefs are concise, peerreviewed articles that present research summaries, novel hypotheses, and emerging findings. We encourage new submissions in this succinct, high-impact format.

The Research Briefs in this issue include topics of relevance to clinicians, patients, and policy makers. Tsunoda and colleagues ${ }^{1}$ share a large case series showing outcomes from a novel technique for patientcontrolled taping to treat ingrown toenails. Based on the results, the authors have made patient-controlled taping the first-line treatment for every ingrown or problematically curved toenail seen in their practice. The article includes links to helpful photos that show the technique.

Another Research Brief will be of value to patients who have problems swallowing pills. ${ }^{2}$ This study evaluates 2 techniques to make it easier to swallow pillsone for tablets, one for capsules - and finds them to be effective. The article includes a patient handout as supplemental material.

The final Research Brief in this issue has both practice and policy implications. For women who have not recently had a mammogram, being hospitalized represents a rarely used opportunity. By examining the amount of money that hospitalized women would be willing to pay toward the cost of a mammogram while in the hospital, Khaliq et al find a high rate of patient acceptance of the idea of doing this screening test as an inpatient. ${ }^{3}$

\section{CLINICAL AND POLICY RESEARCH \& ESSAYS}

Related articles in this issue examine patients' behavioral risks and what to do about them. Using the My Own Health Report (MOHR) assessment and feedback system to support selective counseling and goal setting, the authors find that patients have an average of 6 unhealthy behaviors and mental health risk factors, but only want to change or discuss about 1 of each. ${ }^{4}$ This topic, which has implications for real-world practice, is featured in the Annals Journal Club. ${ }^{5}$ The evaluation of the MOHR intervention pays attention to pragmatic factors that are seldomly studied or reported. The authors find a high rate of implementation and substantial reach into one-half of the patients to whom the assessment was offered, but also identify the need for local adaptation and resource use. ${ }^{6}$

Another study that examined its reach is the BRIGHT trial of disability case finding among patients aged 75 years and older, seen in 60 primary care practices. All 8,308 community-dwelling patients were approached, one-half participated, and three-fourths completed the trial. The intervention resulted in a slight increase in health-related quality of life and residential care placement, and no change in service use, hospitalization, or disability. ${ }^{7}$

A nationwide cohort study in Korea finds a positive effect of continuity of care on mortality, costs, and other outcomes among patients with newly diagnosed cardiovascular risk factors. ${ }^{8}$ Another study furthers the ability to do research on continuity of care by assessing a new measure that can be easily measured in administrative databases. ${ }^{9}$

A study of medical student debt advances the literature on factors associated with students going into primary care. The study examines the different effects of debt based on students' socioeconomic status and attendance at private vs public medical schools. ${ }^{10}$

Two essays provide viewpoints on different policyrelevant questions. Angier et al identify health information technology as an untapped resource to support practice-based efforts to help patients obtain and maintain insurance coverage. ${ }^{11}$ Bodenheimer and Sinsky see the essential and underappreciated peril imposed by health care workforce burnout and dissatisfaction. The authors suggest improving the worklife of clinicians and staff as a fourth item necessary to achieve 
the Triple Aim goal of enhancing patient experience, improving population health, and reducing costs. ${ }^{12}$

We welcome your reflections at http://www. AnnFamMed.org.

\section{TRANSITIONS-THE ANNALS EDITORIAL FELLOW}

We are grateful to Kathleen Rowland, MD, MS for her participation as the Annals' first editorial Fellow. During the past year with us, Kate wrote an editorial, learned about and contributed to editorial, policy, and peer review processes, and advanced the Annals' social media strategy. She also helped us to reflect on, and be grateful for, the relationships and processes that make this work so gratifying. Thank you, Kate.

We are delighted to welcome Aaron Orkin, BASci, $\mathrm{MD}, \mathrm{MSc}, \mathrm{MPH}, \mathrm{CCFP}$ as our new fellow. Aaron is a family and public health physician who currently is completing a fellowship and doctoral degree at the University of Toronto Institute of Health Policy, Management, and Evaluation. Aaron brings to the fellowship a strong interest in the role of expert generalists in patient-centered, effective, and sustainable health care systems, and in the integration of patient-centered and individualized health care models. Welcome, Aaron.

\section{References}

1. Tsunoda M, Tsunoda K. Patient-controlled taping for the treatment of ingrown toenails. Ann Fam Med. 2014;12(6):553-555.
2. Schiele JT, Schneider H, Quinzler R, Reich G, Haefeli WE. Two techniques to make swallowing pills easier. Ann Fam Med. 2014; 12(6):550-552.

3. Khaliq W, Harris CM, Landis R, Bridges JFP, Wright SM. Hospitalized women's willingness to pay for an inpatient screening mammogram. Ann Fam Med. 2014;12(6):556-558.

4. Phillips SM, Glasgow RE, Bello G, et al. Frequency and prioritization of patient health risks from a structured health risk assessment. Ann Fam Med. 2014;12(6):505-513.

5. Frequency and prioritization of patient health risks from a structured health risk assessment [Annals Journal Club]. Ann Fam Med. 2014;12(6):iii.

6. Krist AH, Phillips SM, Sabo RT, et al. Adoption, reach, implementation, and maintenance of a behavioral and mental health assessment in primary care. Ann Fam Med. 2014;12(6):525-533.

7. Kerse N, McLean C, Moyes S, et al. The cluster-randomized BRIGHT trial: proactive case finding for community-dwelling older adults. Ann Fam Med. 2014;12(6):514-524.

8. Shin DW, Cho J, Yang HK, et al. Impact of continuity of care on mortality and health care costs: a nationwide cohort study in Korea. Ann Fam Med. 2014;12(6):534-541.

9. Tousignant $P$, Diop $M$, Fournier $M$, et al. Validation of 2 new measures of continuity of care based on year-to-year follow-up with known providers of health care. Ann Fam Med. 2014;12(6):559-567.

10. Phillips JP, Petterson SM, Bazemore AW, Phillips RL Jr. A retrospective analysis of the relationship between medical student debt and primary care practice in the United States. Ann Fam Med. 2014;12(6):542-549.

11. DeVoe JE, Angier H, Burdick T, Gold R. Health information technology: an untapped resource to help keep patients insured. Ann Fam Med. 2014;12(6):568-572.

12. Bodenheimer T, Sinsky C. From Triple to Quadruple Aim: care of the patient requires care of the provider. Ann Fam Med. 2014;12(6): 573-576.

\section{CORRECTION}

Ann Fam Med 2014;12:499. doi: 10.1370/afm.1724.

Steiner B, Cochella S, Jortberg B, et al. STFM develops preceptor guidelines and a position statement on student use of electronic health records. Ann Fam Med. 2014;12(2)179-180.

The following author names were accidentally omitted from the list of authors for this update: Aaron Michelfelder, MD, FAAFP, FAAMA, and Joel Heidelbaugh, MD, FAAFP, FACG. 